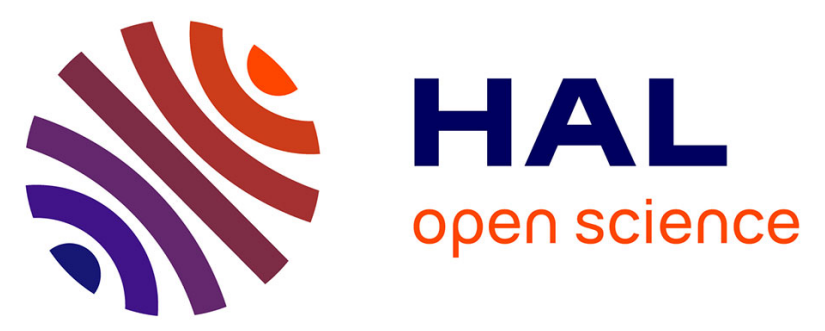

\title{
Greener pharmacy using solvent-free synthesis: Investigation of the mechanism in the case of dibenzophenazine
}

Leslie Carlier, Michel Baron, Alain Chamayou, Guy Couarraze

\section{To cite this version:}

Leslie Carlier, Michel Baron, Alain Chamayou, Guy Couarraze. Greener pharmacy using solvent-free synthesis: Investigation of the mechanism in the case of dibenzophenazine. Powder Technology, 2013, 240 (SI), p. 41-47. 10.1016/j.powtec.2012.07.009 . hal-01631584

\section{HAL Id: hal-01631584 \\ https://hal.science/hal-01631584}

Submitted on 17 Nov 2017

HAL is a multi-disciplinary open access archive for the deposit and dissemination of scientific research documents, whether they are published or not. The documents may come from teaching and research institutions in France or abroad, or from public or private research centers.
L'archive ouverte pluridisciplinaire HAL, est destinée au dépôt et à la diffusion de documents scientifiques de niveau recherche, publiés ou non, émanant des établissements d'enseignement et de recherche français ou étrangers, des laboratoires publics ou privés.

\section{(1) (1) $\$$}

Distributed under a Creative Commons Attribution - NonCommercial - NoDerivatives $\mid 4.0$ 


\title{
Greener pharmacy using solvent-free synthesis: Investigation of the mechanism in the case of dibenzophenazine
}

\author{
Leslie Carlier $^{(\text {a) }}$, Michel Baron ${ }^{(a)} *$, Alain Chamayou ${ }^{(a)}$, Guy Couarraze $^{(\mathrm{b})}$ \\ ${ }^{(a)}$ Ecole des Mines d'Albi-Carmaux, Rapsodee, \\ UMR CNRS 5302, Université de Toulouse, Campus Jarlard, 81013 Albi, France \\ ${ }^{(b)}$ Université Paris Sud 11, UMR CNRS 8612, Laboratoire de Physique Pharmaceutique, \\ Rue Jean-Baptiste Clément, 92296, Châtenay-Malabry Cedex, France \\ *Corresponding author : michel.baron@mines-albi.fr \\ Ph: +33 563493063 \\ Fax: +33 563493025
}

\begin{abstract}
The mechanism of the solvent-free solid-state dibenzophenazine synthesis by dry co-grinding in a vibratory ball-mill has been investigated. The kinetics of the transformation was followed by HPLC and granulometry evolutions were quantified after co-grinding. The mechanism assumed involves a quinone imine intermediate formed during the first step of the reaction (addition of an amino group to a carbonyle) which is favoured by the orbital overlaps between reagents. A water molecule formation occurs during the following step and hydrogen bonds are formed: the water molecule forms a bridge between the reactive centers of the quinone imine, and acts as a catalyst for the completion of the reaction. A push-pull mechanism involving the water bridge is proposed: the energy barrier is reduced by this way. Finally, two thermodynamic drivers favour the dibenzophenazine formation: the increased aromacity number in the product and the stabilization thanks to water molecules.
\end{abstract}

\section{Keywords}

Green Pharmacy, Solvent-free Synthesis, Dibenzophenazine, Push-pull mechanism, Green catalyst, Thermodynamic driver.

\section{Introduction}

Nowadays, more and more sustainable processes are developed for primary and secondary pharmaceutical production. The aim is to follow the principles of green chemistry [1] and green engineering [2] and to adapt these concepts to all kinds of pharmaceutical processes. Among them, the exclusion of organic solvent becomes essential [3]. Many authors proposed using only a small quantity of water $[4,5,6]$ for pharmaceutical operations. Another innovative way consists in using supercritical $\mathrm{CO}_{2}[7,8]$. This option is efficient, but the technology is rather expensive in an industrial point of view. To avoid solvent, the best option is to use no solvent, and recent papers proposed to develop pharmaceutical processes under dry conditions [9, 10], thanks to powder technology resources. 
In the field of primary pharmaceutical production processes, these concepts are also very important, since the molecules are often very complex and poorly soluble, and the total yield of a multistep synthesis is often low, generating a lot of wastes [3]. In order to improve the synthetic yields of active ingredients, some authors suggested the use of microwaves, ultrasounds, ionic liquids, supercritical $\mathrm{CO}_{2}$, catalysts... Others proposed solvent-free syntheses, but the mechanisms are often difficult to understand and were rarely discussed. Watanabe [11] suggested to perform solvent-free Diels-Alder syntheses, in the presence of catalysts to accelerate the reaction and improve the yield. The use of catalyst is obviously interesting. But, because of their high cost and difficulty to recycle them, catalysts must be avoided for the production of pharmaceutical molecules. Their direct elimination is very complex in the case of homogeneous catalysis and even more in solid-state syntheses.

A methodology to synthetize some potential precursors of pharmaceutical active ingredients using solvent-free synthesis, without adding catalyst was proposed recently [12] by our group. The models of precursors chosen were aromatic diazines, and more precisely pyrazines, many natural or synthetic molecules belonging to these series showing potential biological activities in particular as antibacterial [13] and antitumor agents $[14,15,16]$.

In the present paper, an investigation of the mechanism has been done, and a mechanism is suggested in order to explain kinetic data, in a perspective of developing the knowledge of this solid-state transformation and to further develop the processes of co-milling of powders, and their applications to industrial production.

\section{Synthesis chemical equation}

The synthetical pathway is shown in Scheme 1. The 9,10-phenanthrenequinone reacts with 1,2 o-phenylenediamine in equimolar ratio to give the dibenzo[a,c]phenazine (compound 1.) [12].

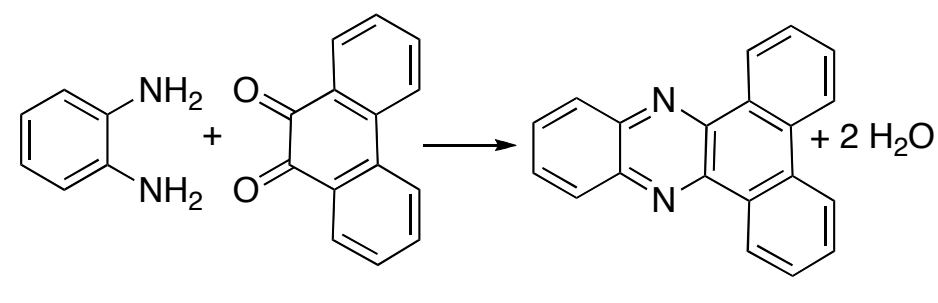

1

Scheme 1. Synthesis of the dibenzo[a,c]phenazine.

\section{Materials and method}

\section{3-1 General}

The synthesis was performed using $2 \mathrm{~g}$ of an equimolar ratio of both reactants (from SigmaAldrich, USA) in an agate vibrating ball-mill Pulverisette 0 (Fritsch, Germany) during $4 \mathrm{~h}$, under atmospheric conditions. The agate ball mass was $180 \mathrm{~g}$, and the vibration amplitude was $2.5 \mathrm{~mm}$. 


\subsection{Particle size distribution measurements}

After vibratory ball-milling, the size distribution of the produced particles has been determined by laser diffraction method using a Malvern Mastersizer 2000 device in dry way (dispersion in air - dispersing air pressure: 3.5 bars). These measurements were performed $24 \mathrm{~h}$ or more after the grinding experiments.

\subsection{Chemical kinetics}

The chemical kinetics was followed using HPLC (High Performance Liquid Chromatography).

Chromatographic separation was carried out on an extend $\mathrm{C}_{18}$ column $(4,6 \times 250 \mathrm{~mm}, 5 \mu \mathrm{m}, 300$ $\AA$, Vidac 201 TP 54). A mixture of acetonitrile (40) / tributylammonium in aqueous solution $3 \mathrm{mMolar}(60)$ was used as the mobile phase. All the experiments were performed at $254 \mathrm{~nm}$.

\section{Results}

\subsection{Study of the kinetics}

HPLC has been used to quantify the yield of dibenzo[a,c]phenazine. The measurements have been performed immediatly after co-grinding (A) and 24 hours later (B) (Figure 1).

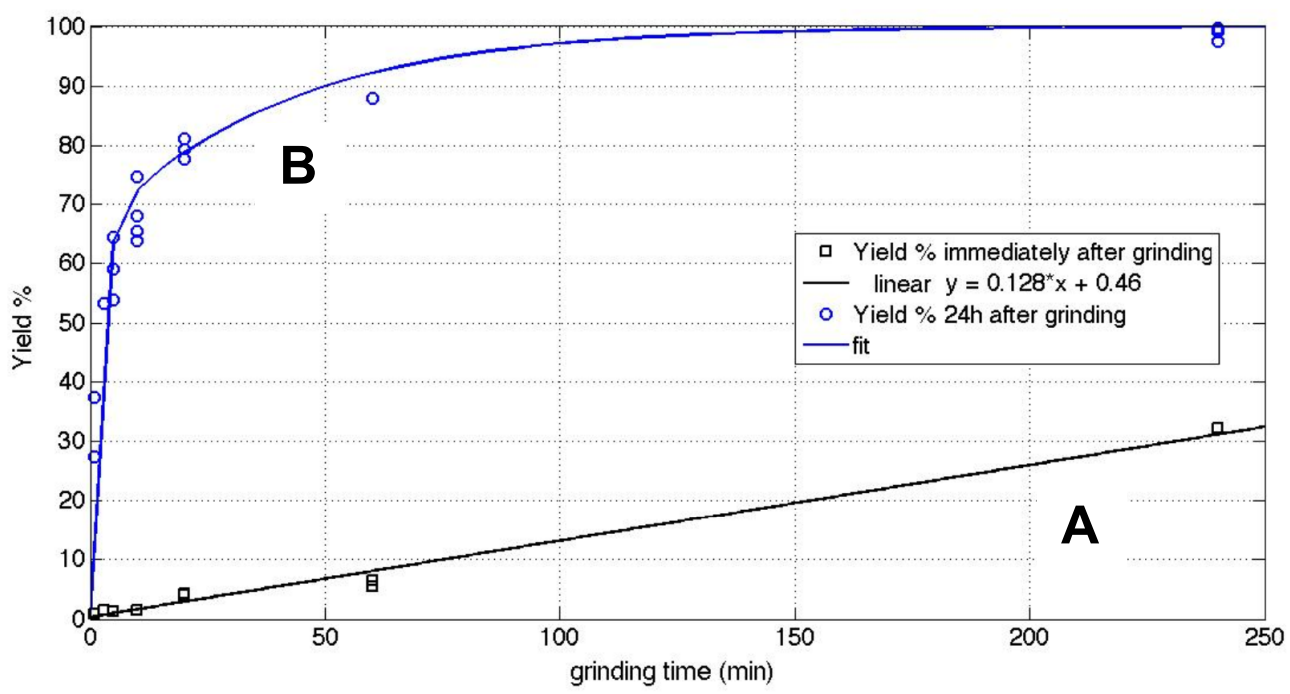

Fig.1 Kinetics of the reaction

\subsection{Particle size distribution measurements}

The evolution of the PSD of both reactants ground separately and co-ground mixture has been observed and is described in Figures 2 and 3. Concerning the o-phenylene diamine (OPD), Figure 2 -a shows that crude material presents a large amount of very coarse particles $\left(\mathrm{d}_{50}=660 \mu \mathrm{m}\right)$ that are rapidly broken ( $\mathrm{d}_{50}=8,9 \mu \mathrm{m}$ after $5 \mathrm{~min}$ grinding).

Crude 9,10-Phenanthrenequinone (PQ) which is a finer product $\left(\mathrm{d}_{50}=20,8 \mu \mathrm{m}\right)$ than crude OPD, shows more resistance against the grinding process $\left(\mathrm{d}_{50}=14,6 \mu \mathrm{m}\right.$ after $5 \mathrm{~min}$ grinding $)$. A very 
slow abrasion-like size reduction combined with a phenomenon of agglomeration is observed (Figure 2-b).

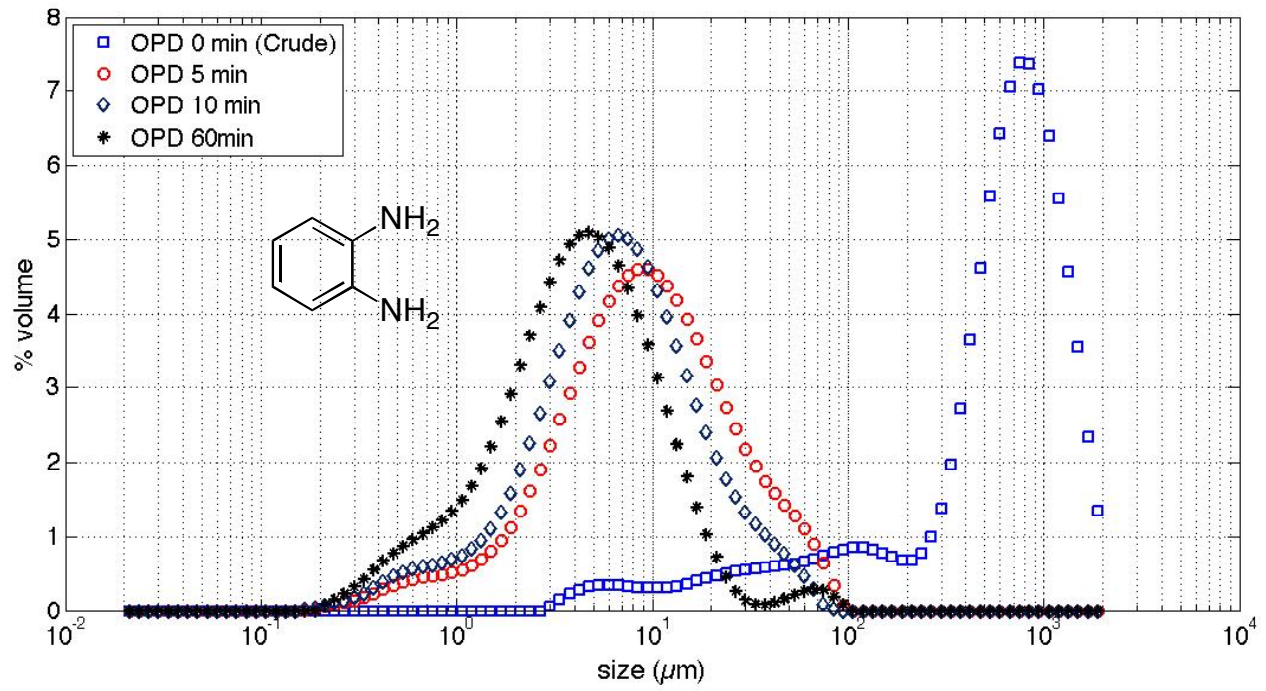

a) Size evolution of OPD particles during vibratory ball-milling

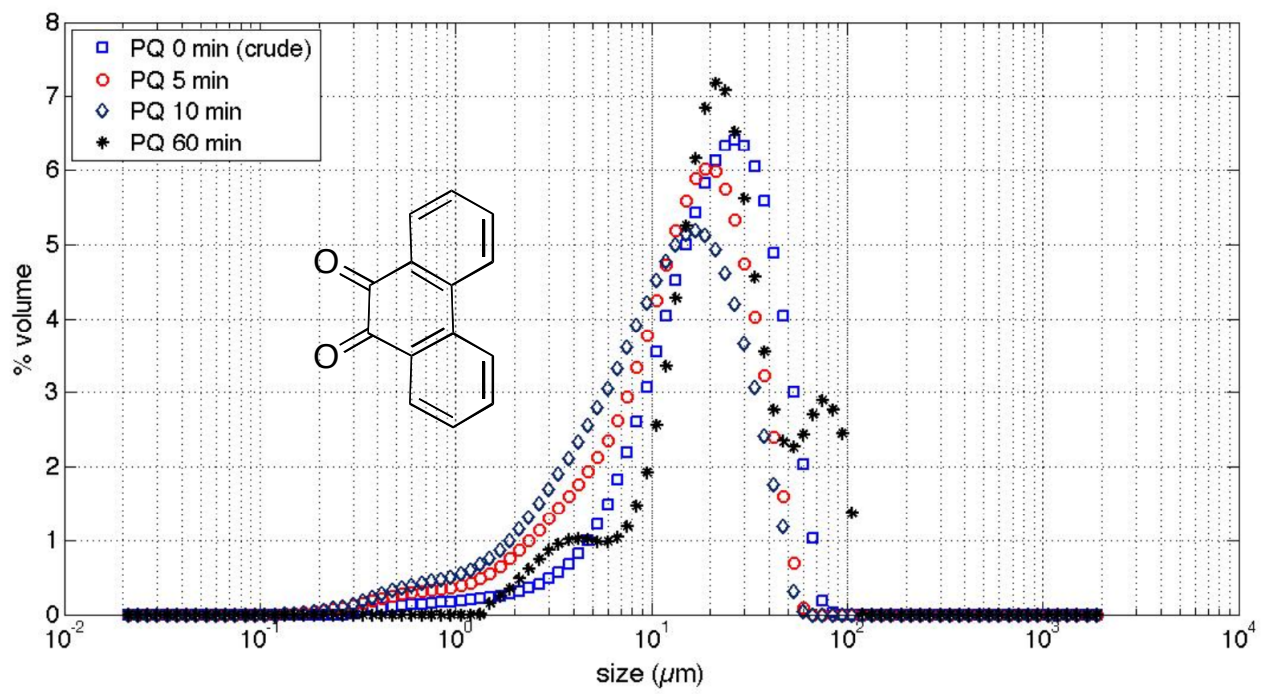

b) Size evolution of PQ particles during vibratory ball-milling 


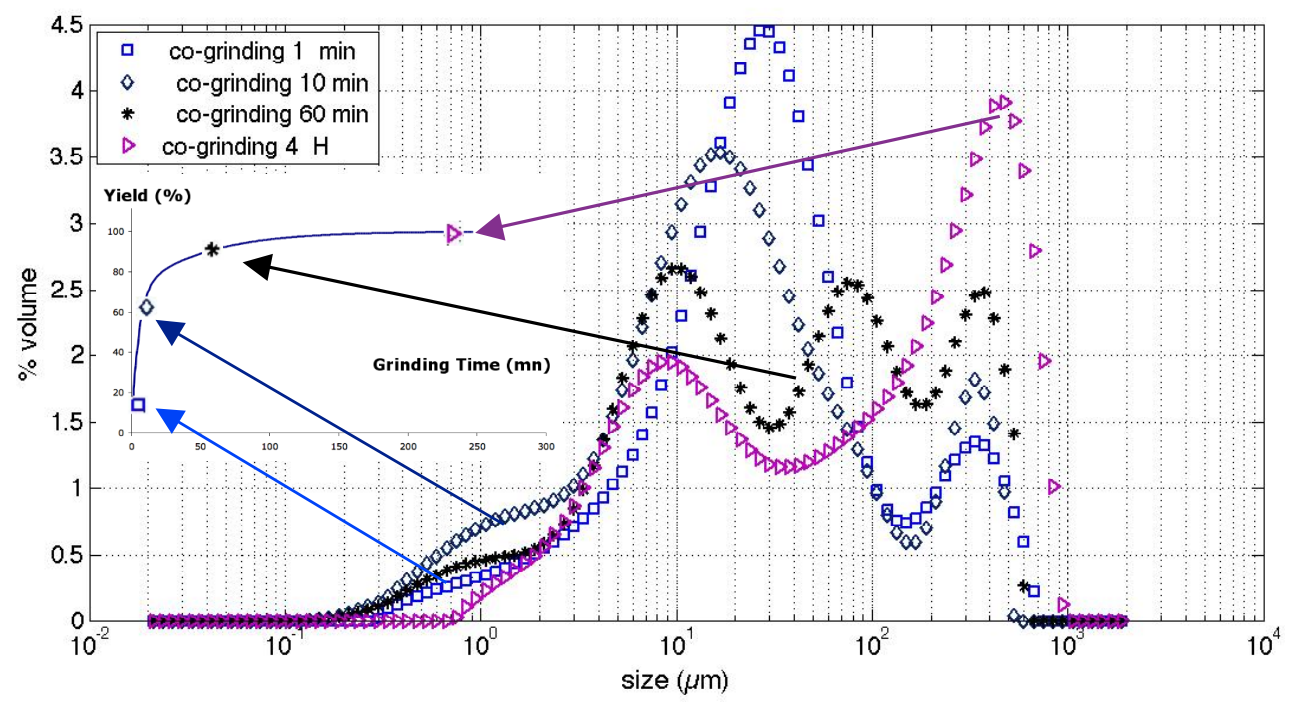

c) Evolution of the particle size during the synthesis by vibratory ball-milling, parallel to the kinetics

Fig. 2. Evolution of the Particle Size Distribution (PSD) of the reagents separately ground or co-ground

Co-grinding process presents a characteristic PSD evolution (Figure 2-c) : after one mn, then 10 mn co-grinding, more fines appear, and gradually a small peak appears at $200-300 \mu \mathrm{m}$. After $1 \mathrm{~h}$ co-grinding, a new peak appears around $80 \mu \mathrm{m}$, and the peak around $200-300 \mu \mathrm{m}$ shifts towards $300-400 \mu \mathrm{m}$. Finally after $4 \mathrm{~h}$, the main population is located around $400-500 \mu \mathrm{m}$, suggesting an important agglomeration mechanism of the fine particles previously formed. This agglomeration is concomitant with the chemical reaction and suggests a reactive agglomeration. The peak around $80 \mu \mathrm{m}$ appearing after $1 \mathrm{~h}$ co-grinding could be linked to the presence of intermediate states including crystallites of the final product mixed to some reagents remaining in the mixture (mainly as fine particles), and a majority of final product (mainly agglomerated).

Figures 3-a to 3-c present a more accurate comparison between OPD, PQ and co-ground products at different treatment times that reinforce the previous interpretation. A disappearance of the main peaks observed for the separately ground reagents can be noticed as well as an important agglomeration (peak at $400-500 \mu \mathrm{m}$ ) for the co-ground product in particular. 


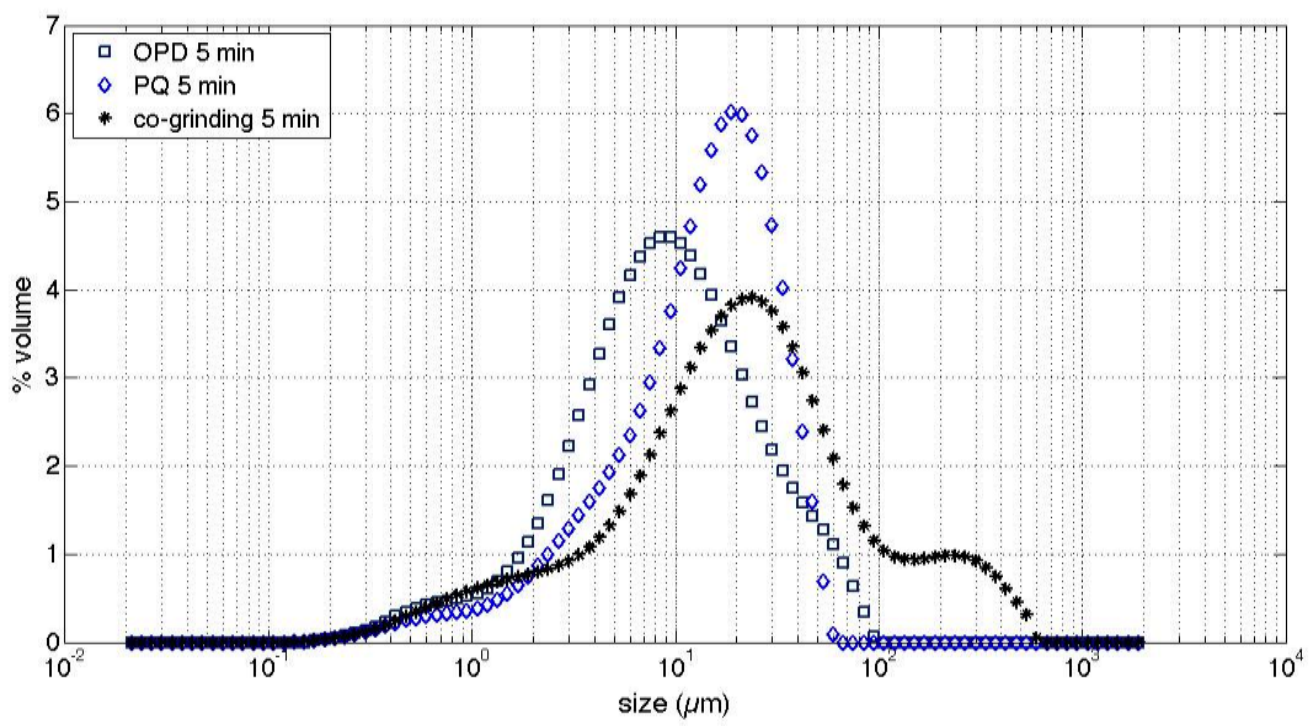

a) PSD after $5 \mathrm{mn}$

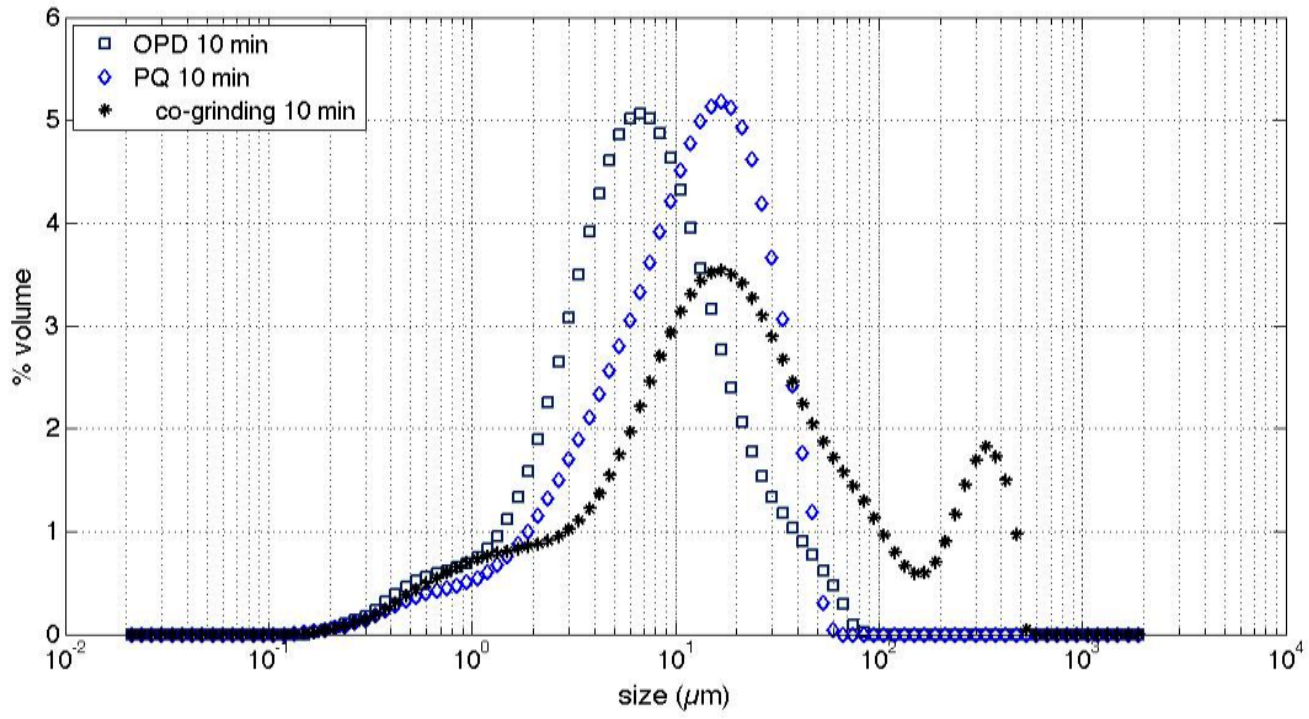

b) PSD after $10 \mathrm{mn}$ 


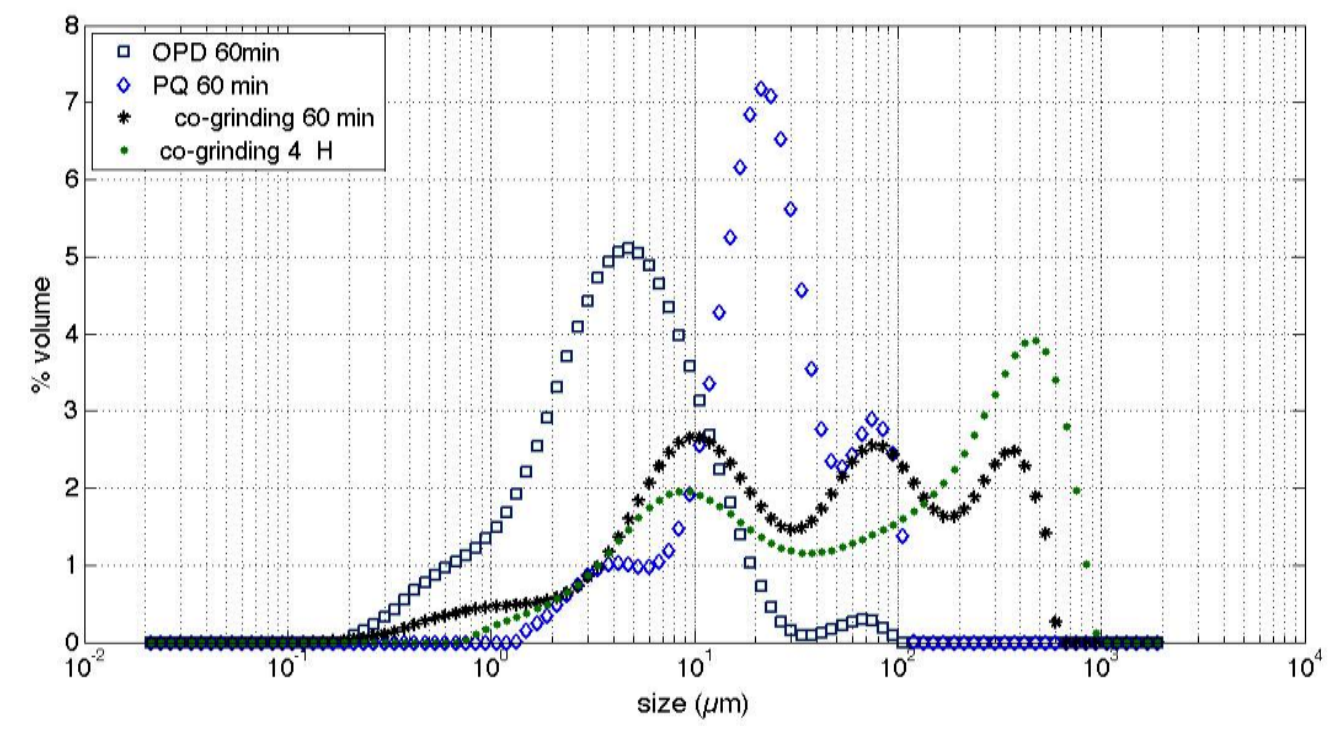

c) PSD after $60 \mathrm{mn}$ (and $4 \mathrm{~h}$ for the co-ground reagents)

Fig. 3. Comparison of the Particle Size Distribution (PSD) of the reagents ground separately or co-ground, at different times

\section{Discussion}

\subsection{Overview of the mechanism (scheme 2)}

The restricted number of intermolecular contacts between dissimilar reactant species is a major obstacle for a solid state reaction. When a chemical reaction involves the reaction of two reagents reacting by two different centers, during a solid phase co-grinding and in the absence of catalyst, the reaction can take a longer time than the same reaction in a solvent, since this phenomena is a stochastic one. This restriction was experimented for instance by Watanabe [11], who proposed to add phenolic catalysts in order to accelerate Diels-Alder solvent-free reaction carried out in a vibratory ball-mill.

The curve A (Fig. 1), shows a zero order kinetics. According to the granulometric results, we can postulate that the mechanism begins by a fine grinding of the reagents particles (mainly for ophenylenediamine), known as a factor accelerating the contact between particles [17]. The intimate mixing of the reagents, under the cyclic pressure due to the movement of the ball, favours the addition of an amino group to a carbonyl one. In the case of the vibratory ball-mill used to explore the feasibility of the process, only a small part of the powder is located at the impact zone under the ball during the grinding [18], the energy brought to the system is proportional to the grinding time, and the transformation is proportional to the time, as observed in the curve A.

In the formation of aromatic diazines like phenazine or quinoxaline, two main steps are at least involved for each amino group (each step includes an addition to a carbonyl group, followed by the elimination of a water molecule) (Scheme 2). 


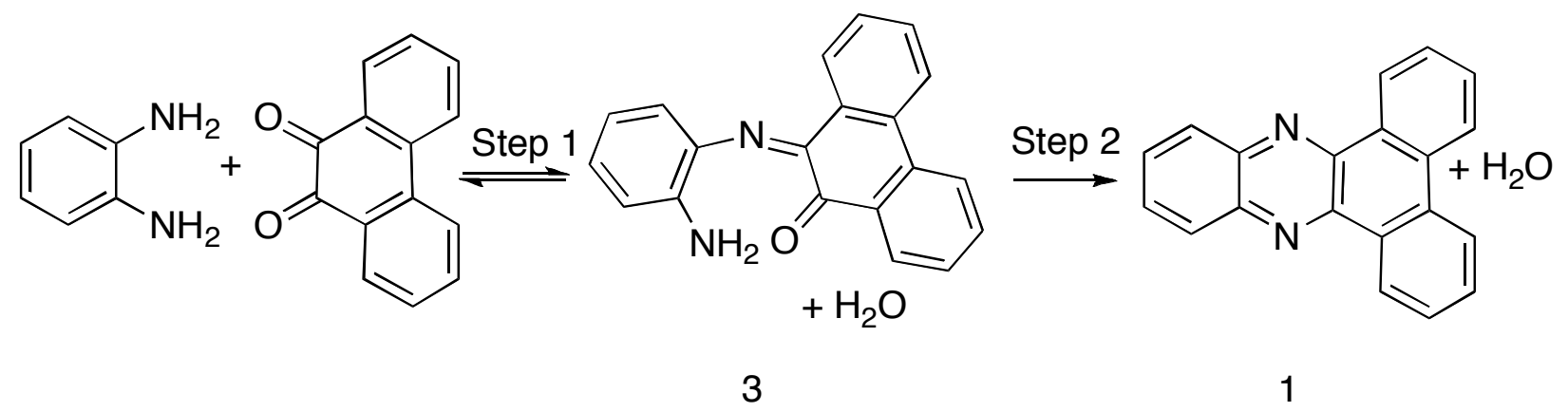

Scheme 2. The two steps of the dibenzo[a,c]phenazine synthesis

After the obtention of the finely ground intimate mixture, the second step involving the second amino group could occur even without mechanical action, if the internal mobility of the intermediate 3 and its stereoselectivity ( 3 can have an $\mathrm{E}$ or $\mathrm{Z}$ configuration, and the transformation from one configuration to the other is possible, due to the reversibility of the imine formation) is sufficient. As a matter of fact, this second step is driven by thermodynamics, the dibenzo[a,c]phenazine 1 being strongly stabilized by the formation of the new aromatic ring. This mechanism could explain the curve B (Fig. 1, 2c). This curve B is compatible with the granulometric analysis (see 4.2). After one hour co-grinding, the total disappearance of the main peaks of the 9,10-phenanthrenequinone, and of the o-phenylenediamine is observed. At the same time, the granulometric analysis (Fig. 2c) shows a triple wave and the new peak located around $80 \mu \mathrm{m}$ could suggest the nucleation of the crystallites of the final product, the yield of dibenzo[a,c]phenazine around $90 \%$ not allowing the total agglomeration of the final product, since some materials or intermediates probably remain in the mixture. It must be noticed that even if the 9,10-phenanthrenequinone disappears almost totally from the mixture, it could be converted into an intermediary, as for instance the quinone-imine 3 (Scheme 2), and not totally transformed yet into the final product quantified by HPLC. If no intermediate was clearly detected in HPLC (probably due to the fleetingness in solution of these intermediates in the case of a thermodynamically driven reaction, see 5.2.2.2.), after 4 hours co-grinding, the curve B (Fig. $1,2 \mathrm{c}$ ) shows a total transformation into the dibenzophenazine 1 . At the same time, the particle size distribution (Fig. 2c) is drastically changed, showing a strong agglomeration of this final product 1 (see section 4.2 ).

\subsection{Investigation of the detailed mechanism}

The molecular mechanisms of solvent-free synthesis are difficult to establish and are rarely studied [19]. But investigating the mechanisms is particularly useful during industrial scaling-up to control the critical parameters of the processes. Some authors postulated that the mechanism went through the formation of an eutectic since the reaction seems easier at the molecular level in a melted liquid phase. [20]. But the Wittig synthesis carried-out in a solid phase does not involve a liquid intermediary phase [21]. The transitory formation of charge-transfer complexes was also suggested [11], as was postulated the reduction of the gap between bonding and antibonding orbitals [21] allowing reactions thanks to an « inverse Jahn-Teller effect» [23]. The possibility of electronic tunnel effect minimizing the energetic level of the transition state was also proposed [24], or the passage through radicalar pathways [25, 26, 27]. This shows that many possibilities 
exist, depending on the reagents and the experimental conditions, and leading to various mechanisms. The bending of the bonds and the deformation of orbitals during mechanical action can generate reactions or products not expected according to the usual rules of organic chemistry, as the Woodward-Hoffmann rules [28]. In the present case, we propose two steps :

\subsubsection{Step 1 : obtention of the quinone-imine.}

\subsubsection{Initial orbitals overlap (Scheme 3).}

The polarity of the reagents should allow a ionic reaction similar to the reaction observed in a liquid phase, but without solvatation, since no solvent is available. Particles and molecules are very close during co-grinding and this phenomenon allows a charge transfer between the reactants, and an overlap of orbitals (Scheme 3), similar to the previously reported case of the reaction of calcium oxide with various silicon, aluminium, titanium oxides [29, 30]. The orbitals overlap is favoured by the intimate mix of the particles. The electronic doublet of one nitrogen of o-phenylenediamine attacks the carbon from the carbonyl group of the 9,10-phenanthenequinone into its antibonding orbital (Scheme 4). 


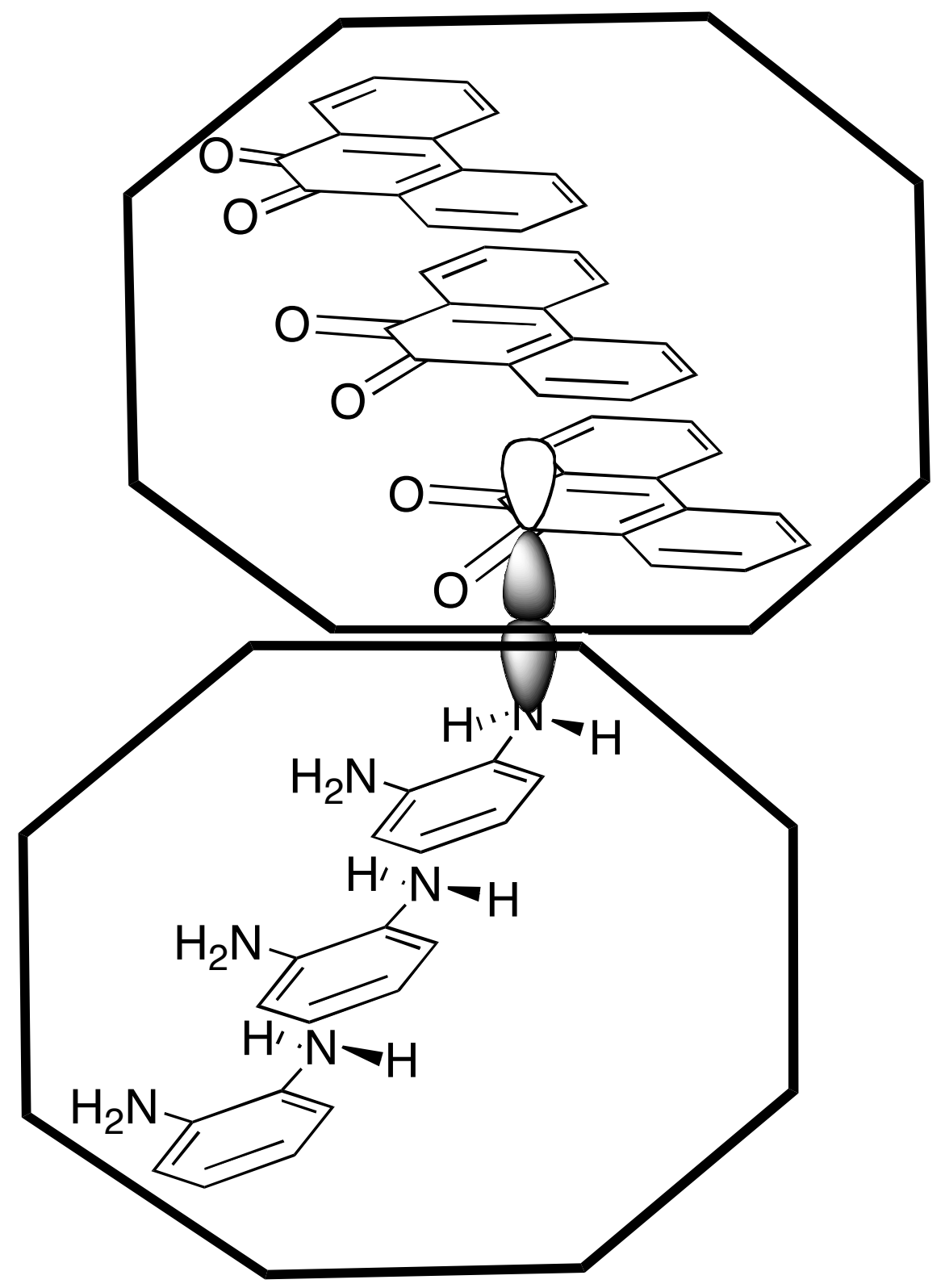

Scheme 3. Orbitals overlap leading to C-N bond (the octogons symbolize the particles) 

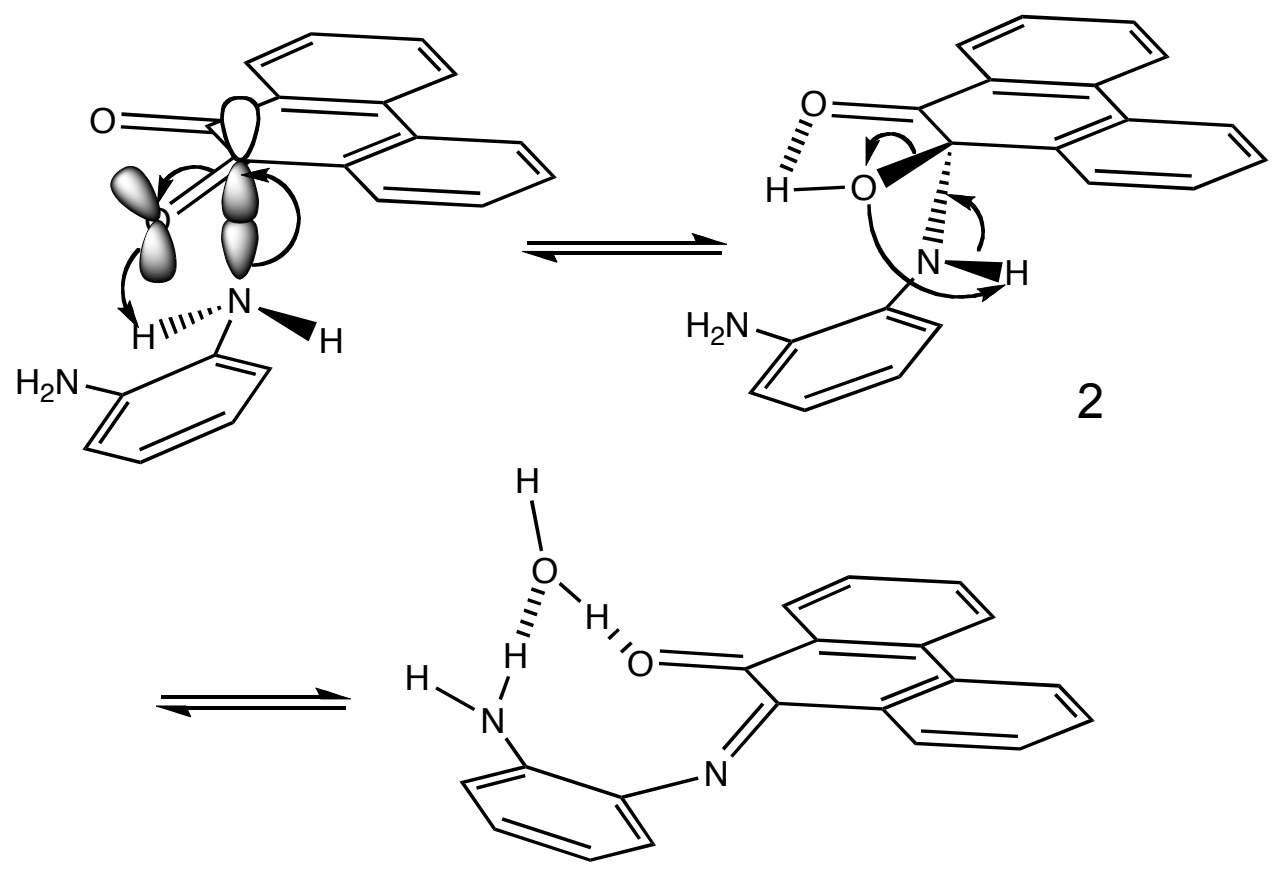

3

Scheme 4. Formation of the quinone-imine 3 by addition/elimination

\subsubsection{Elimination of one water molecule (Scheme 4).}

As soon as the overlap of orbitals takes place, the formation of the amino-alcool 2 occurs, transformed into the quinone-imine 3 by elimination of one molecule of water. This water molecule can form a bridge between the second amino group and the second carbonyl group, and is linked by hydrogen bonds to the quinone-imine. This phenomenon allows the obtention of a $\mathrm{Z}$ configuration of the quinone-imine, which is suitable for the step 2.

\subsubsection{Step 2 :Obtention of the dibenzophenazine.}

\subsubsection{Push-pull mechanism using one molecule of water as catalyst, and formation of an amino-alcool.}

As mentioned before (5.1.), a solid-state reaction involving two different molecular active centers is a stochastic process which is the main difficulty. In the present case, when the water molecule is formed close to the quinone-imine 3, its mobility is favoured by its size and flexibility. This water molecule can make a bridge between the second amino group and the carbonyl group of the freshly prepared quinone-imine (4., Scheme 5). This water molecule could then act in situ as a green catalyst decreasing the energetic barrier of the second step. A push-pull mechanism is proposed (Scheme 5) for the formation of the amino-alcool 5 (Scheme 6). 


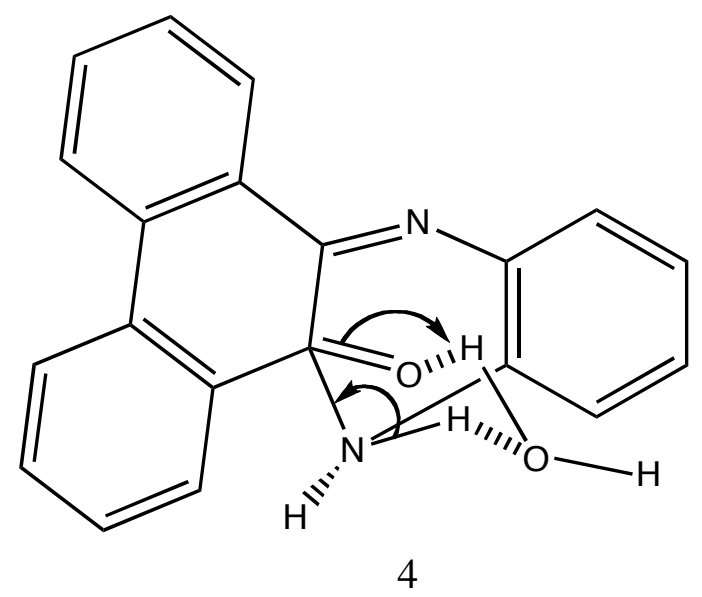

Scheme 5 . Transition state (4.) and «push-pull» mechanism

If hydrogen bonds can play a role facilitating and accelerating specific organic reactions involving stabilized transition states [31], the intervention as a catalyst of a water molecule complexed in the transition state, is unusual in classical thermal organic syntheses. This mechanism proposed in this solvent-free synthesis involving one molecule of water acting as a green catalyst should be compared to the mechanisms promoted by enzymes in a biological environment [32]. It is easy to imagine that this transition state (4., Scheme 5), stabilized by the water bridge is destabilized by a too much intense continuous stirring of the mixture by the ball movement, just as a transition-state of a complex between an enzyme and a substrate is destabilized by temperature.

\subsubsection{Final driving by thermodynamics (Scheme 6)}

In the case of mechanical alloying of metallic systems, it was established that the mechanical activation can be driven by thermodynamic driving forces [33]. For the present organic reaction, the formation of the final dibenzophenazine is favoured by two factors: the additional aromatic system and the formation of H-bonds stabilizing the crystalline structure. The formation of complexes of phenazine with water molecules bound by hydrogen bonds has been reported by Choudhuri [34], and the formation of a pseudopolymorph of methyldibenzophenazine was demonstrated recently [12]. 

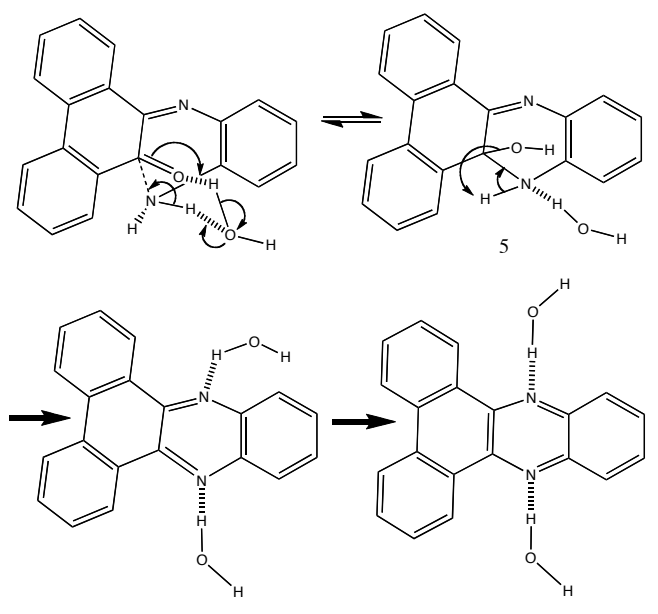

Scheme 6. Step 2 : Addition/elimination generating dibenzo[a,c]phenazine

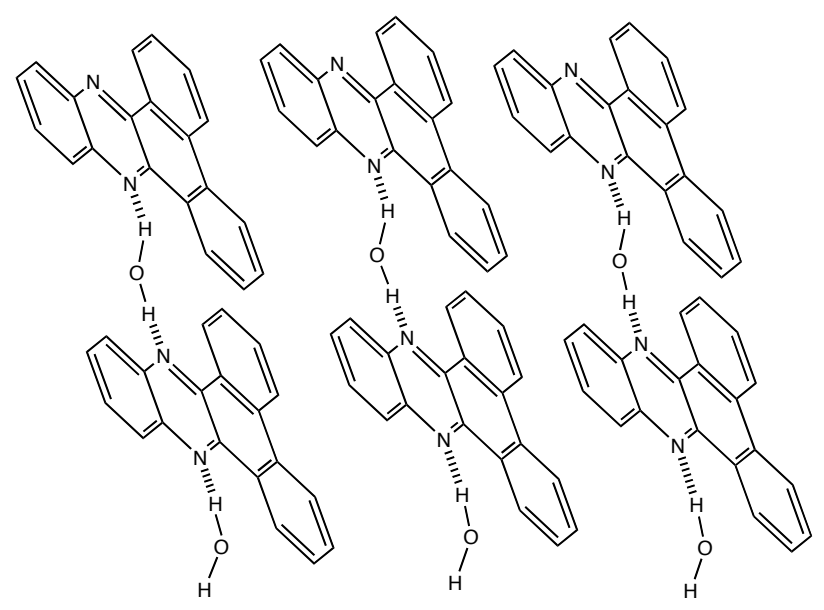

Scheme 7. Schematic representation of the hydrated dibenzo[a,c]phenazine (1)

Then, after the step 1 (Scheme 4), the successive transition state stabilized by the water molecule (Scheme 5), and the final aromatic nucleus acting as a thermodynamic driver (Scheme 6) can explain the two curves A and B of the kinetics (Fig.1). The curve A shows a stochastic reaction, mainly piloted by the continuous co-grinding, increasing the statistical percentage of collision of the reactive sites, but at the same time destabilizing a preferential transition state including the water bridge (Scheme 5). The curve B can be explained, after initial co-grinding, by a statical reaction catalysed by this molecule of water decreasing the energetic level of the transition state, and the free energy barrier to reaction, and finally piloted by thermodynamic drivers: the new aromatic nucleus, and the hydrated pseudo-polymorph of the dibenzophenazine (Scheme 7). This hypothesis of mechanism was confirmed by the evolution of the granulometry of particles during the co-grinding, showing a beginning of reaction after one minute, and a good transformation yield after 1 hour grinding, and finally a total transformation accompanied by a strong particles agglomeration after 4 hours co-grinding.

\section{Conclusion}

A dibenzo[a,c]phenazine, considered as a model of potential active ingredients precursor, was successfully synthesized by solvent-free synthesis, using dry co-milling of powders in a singleball vibrating ball-mill. The yield and purity of the product were very good, showing perspectives in the area of sustainable green chemistry and pharmacy.

In order to explain the kinetics of the reaction, the mechanism occurring in the solid state was investigated. A push-pull mechanism was proposed, using a molecule of water generated during the first step of the synthesis, bridging two reacting centers of the quinone-imine, and acting as a green benign catalyst (as in the case of enzymes in biological reactions). This reduces the freeenergy barrier of the chemical transformation after initiation by mechanical action, and potentially generates energy saving during the synthesis, in a perspective of industrial 
application. This mechanism was corroborated by the analysis of the reaction kinetics, of the granulometry, and in consideration of the obtention of an hydrated form of the dibenzophenazine. This method creating in situ and using a green catalyst must be taken into consideration as one of the possible tools among the arsenal existing in process engineering, to control, design and develop more sustainable primary and secondary pharmaceutical production processes.

\section{Acknowledgements}

Philippe Accart is sincerely acknowledged for the realization of the particle size measurements.

\section{References}

[1] P.T. Anastas and J.C. Warner, Green Chemistry, Theory and Practice, Oxford Sciences Publications, New-York, 1998.

[2] P.T. Anastas, J.B. Zimmerman, Design through the Twelve Principles of Green Engineering, Environ. Sci. and Technol., 37 (5)(2003) 94A-101A.

[3] J. Andraos, Unification of Reaction Metrics for Green Chemistry: Applications to reaction analysis, Org. Process Res. Dev., 9 (2)(2005) 149-163.

[4] A. Gil, A. Chamayou, E. Leverd, J. Bougaret, M. Baron, G. Couarraze, Interaction of a new chemical entity, Eflucimibe, with $\gamma$-cyclodextrin using kneading method, Eur. J. Pharm. Sci., 23 (2004) 123-129.

[5] A. Desiré, B. Paillard, J. Bougaret, M. Baron, G. Couarraze, A comparison of three extrusion systems - Part II: Influence of formulation and spheronization conditions on pellet properties, Pharm. Technol., 35 (2011) 56-65.

[6] C. Gendre, M. Genty, M. Boiret, M. Julien, L. Meunier, O. Lecoq, M. Baron, P. Chaminade, J-M. Péan, Development of a Process Analytical Technology (PAT) for in-line monitoring of film thickness and mass of coating materials during a pan coating operation, Eur. J. Pharm. Sci. 43 (2011), 244-250.

[7] I. Pasquali, R. Bettini, F. Giordano, Solid-state chemistry and particle engineering with supercritical fluids in pharmaceutics, Eur. J. Pharm. Sci., 27 (2006) 299-310.

[8] J. Fages, E. Rodier, A. Chamayou, M. Baron, Comparative study of two processes to improve the bioavailability of an active pharmaceutical ingredient: kneading and supercritical technology, Kona, 25 (2007) 217-229.

[9] Y. Ouabbas, J. Dodds, A. Chamayou, L. Galet, M. Baron, Particle-particle coating in a cyclomix impact mixer, Powder Technol., 189 (2009) 245-252.

[10] L. Galet, Y. Ouabbas, A. Chamayou, P. Grosseau, M. Baron, G. Thomas, Surface analysis of silicagel particles after mechanical dry coating with magnesium stearate, Kona, 28 (2010) 209218.

[11] H. Watanabe, R. Hiraoka, M. Senna, Diels-Alder reaction catalysed by eutectic complexes autogeneously formed from solid state phenols and quinones. Tetrahedron Lett. 47 (2006), 44814484.

[12]. L. Carlier, M. Baron, A.Chamayou, G. Couarraze, Use of co-grinding as a solvent-free solid state method to synthesize dibenzophenazines, Tetrahedron Lett. 52 (2011), 4686-4689.

[13] A. Dell, D.H. Williams, H.R. Morris, G.A. Smith, J. Feeney, G.C.K. Roberts, Structure revision of the antibiotic echinomycin, J. Am. Chem. Soc, 97 (9) (1975) 2497-2502. 
[14] J. Renault, M. Baron, P. Mailliet, S. Giorgi-Renault, C. Paoletti, S. Cros, Hétérocycles à fonction quinone. II : Quinoxalinediones-5,6 et $-5,8$ à action antitumorale potentielle, Eur. J. Med. Chem, 16 (1981) 545-550.

[15] S. Giorgi-Renault, J. Renault, M. Baron, et al, Heterocyclic quinones. Dimerization in the series of 5,8-Quinazolinediones- Synthesis and antitumor effect of bis (4-amino-5,8quinazolinediones). Chem. Pharm. Bull., 36 (1988), 10, pp 3933-3947.

[16] J-C. Chen, L. Qian, W-J. Wu, L-M. Chen, K-C. Zheng, A QSAR study of substituted benzo[a] phenazines as potential anticancer agents, J. Mol. Struct.Theochem, 756 (2005) 167-172.

[17] A.Y. Ibrahim, R.T. Forbes, N. Blagden, Spontaneous crystal growth of co-crystals : the contribution of particle size reduction and convection mixing of the co-formers, Cryst. Eng. Com., 13 (4) (2011), 1141-1152.

[18] H. Huang, M.P. Dallimore, J. Pan, P.G. McCormick, An investigation of the effect of powder on the impact characteristics between a ball and a plate using free falling experiments, Mat. Sci. and Eng. A 241 (1-2) (1998) 38-47.

[19] V. V. Boldyrev and E.V. Boldyreva, Mechanochemistry and mechanical activation of solids, part 2, Experimental and theoretical studies in Modern Mechanochemistry, in: F. Delogu, G. Mulas (Eds.), Experimental and theoretical studies in Modern Mechanochemistry, Transworld Research network, Trivandrum, 2010, pp 21-39.

[20] G.W.V. Cave, C.L. Raston, J.L. Scott, Recent advances in solventless organic reactions : toward benign synthesis with remarkable versability, Chem. Commun. , 21 (2001), 2159-2169.

[21] K.C. Nguyen, H. Weizman, Greening Wittig reactions: Solvent-free synthesis of Ethyl trans-cinnamate and trans-3(9-anthryl)-2-propenoic acid ethyl ester. J. Chem Ed., 84 (2007), 1 $119-121$.

[22] J.J. Gilman, Mechanochemistry, Science, 274 (1996), 65-65.

[23] T. Luty, P. Ordon, C.J. Eckardt. A model for mechanochemical transformations: Applications to molecular hardness, instabilities, and shock initiation of reaction. J. Chem. Phys., 117 (2002), 4 - 1775-1785.

[24] V.M. Tapilin, N.N. Bulgakov, A.P. Chupakhin, A.A. Politov, On the mechanism of mechanochemical dimerization of anthracene. Quantum-chemical calculation of the electronic structure of anthracene and its dimer, J. Structural Chem. 49 (2008), 4, 581-586.

[25] Q. Zhang, J. Lu, F. Saito, M. Baron, Mechanochemical solid-phase reaction between polyvinylidene fluoride and sodium hydroxide, J. Appl. Polym. Sci. 81 (2001), 9, 2249-2252.

[26] Q. Zhang, H. Matsumoto, F. Saito, M. Baron, Debromination of Hexabromobenzene by its co-grinding with $\mathrm{CaO}$, Chemosphere, 48 (2002) 787-793.

[27] J. Raffi, S. Gelly , L. Barral, F. Burger, P. Piccerelle, P. Prinderre, M. Baron, A. Chamayou, Electron paramagnetic resonance of radicals induced in drugs and excipients by radiation or mechanical treatments. Spectrochim Acta A Mol Biomol Spectrosc., 58 (2002) (6):1313-20

[28] G.S. Kochhar, A. Bailey, N. Mosey, Competition between orbitals and stress in mechanochemistry, Adgew. Chem. Int. Edit., 49 (2010), 41, 7452-7455.

[29] E.G. Avvakumov, E.T. Devyatkina, N. V. Kosova, Mechanochemical reactions of hydrated oxydes, J. Solid State Chem., 113 (1994), 2, 379-383.

[30] M. Senna, Chemical powder technology- a new insight into atomic processes on the surface of fine particles, Adv. Powder Technol., 13 (2002), 2, 115-138.

[31] M. Baron, S. Giorgi-Renault, J. Renault, P. Mailliet, D. Carré, J. Etienne, An abnormal reaction of butanedione with diamino-1,2 anthraquinone; crystalline structure of the naphto(2,3f)quinoxalinedione-7,12 obtained. Can. J. Chem., 62 (1984), 526-530. 
[32] R.J.P. Williams, A comparison of types of catalyst: The quality of metallo-enzymes, J. Inorg. Biochem., 102 (2008), 1-25.

[33] S. Kaloshkin, V. Tcherdyntsev, Thermodynamic driving forces of phase transformations under MA processing, in: F. Delogu, G. Mulas (Eds.), Experimental and theoretical studies in Modern Mechanochemistry, Transworld Research network, Trivandrum, 2010, pp. 57-72.

[34] S.D. Choudhuri, S. Basu, Interaction of phenazine with water and DNA bases, Spectrochim. Acta A 62 (2005) 736-739. 